\title{
Summary.
}

In this article we have presented experimental evidence to show that ultra-violet light will precipitate colloidal platinum out of solutions that are free from electrolyte except the carbon dioxide of the air, or that due to the dissolution of hard glass.

We have also shown that when electrolytes are present their precipitating effect is very greatly accelerated by the action of ultra-violet rays.

The action of the ultra-violet light was shown to be greater in dilute sclutions of the colloid than in the more concentrated.

Cambridge, 39, Mass.

[CONTRIBUtion From the Chemistry Defartment of Columbia University, No.360.]

\section{THE APPLICATION OF IDEAL SOLUTION EQUATIONS TO DILUTE AQUEOUS SOLUTIONS.}

\author{
By James Kendali. \\ Received April 27, 1920.
}

The relative lowering of the vapor pressure of water by addition of a normal, non-volatile solute is such a fundamental point in the study of solutions that one would expect physical chemists, at this late date, to have agreed upon some definite theoretical treatment of the topic. An examination of the literature will show, however, that this is far from being the case. In the following pages a brief analysis of the present situation is made, and an explanation of existent discrepancies indicated. The erroneous interpretation now given to certain equations derived from the law governing vapor-pressure depression for ideal solutions, when applied to aqueous solutions, is also discussed.

The Dilute-Solution Equation.-Most introductory text-books ${ }^{1}$ follow Arrhenius ${ }^{2}$ in deriving the equation for the vapor pressure of highly dilute solutions from van't Hoff's gas law for osmotic pressure, obtaining the relation ${ }^{3}$

$$
\left(p_{0}-p\right) / p_{0}=n / N
$$

where $p_{0}$ is the vapor pressure of pure solvent, $p$ the vapor pressure of solution, and $n / N$ is the ratio of the number of solute molecules to the number of molecules which the solvent would produce if converted into

${ }^{1}$ For example, Walker, "Introduction to Physical Chemistry," 1913, p. 193; Lehfeldt, "Physical Chemistry," p. 29.

${ }^{2}$ Arrhenius, $Z$. physik. Chem., 3, 115 (1889).

3 This relation is strictly valid only for solutions of infinite dilution, constituting the limiting case of the more exact equation: $\ln \left(p_{0} / p\right)=n / N$. The difference between the calculated values for the two forms of the equation is, however, inappreciable even for a fairly concentrated solution. For an example see Lehfeldt, op. cit., p. 31 . 
vapor. The words in italics are vitally significant in the case of an associated solvent such as water. ${ }^{4}$

The experimental data for dilute aqueous solutions (although few determinations of a high order of accuracy are available) are in good agreement with the above equation. The results of Frazer and Lovelace ${ }^{5}$ for mannite solutions may be cited: 6

\begin{tabular}{|c|c|c|c|c|c|}
\hline $\begin{array}{c}{ }^{T} \dot{\mathrm{C}} . \\
20.008\end{array}$ & $\begin{array}{c}\text { Conc. (wt. molar). } \\
0.4\end{array}$ & $\begin{array}{c}p_{0}-p . \\
\mathrm{mm} . \\
0.122\end{array}$ & $\begin{array}{l}\text { po. } \\
\text { mm. } \\
17.548\end{array}$ & $\begin{array}{c}\left(p_{o}-p\right) / p \\
(o b s .) \\
0.070\end{array}$ & $\begin{array}{c}\left(p_{0}-p\right) / p_{0} \\
\text { (calc.) } \\
0.072\end{array}$ \\
\hline 20.036 & 0.5 & 0.156 & 17.578 & 0.089 & 0.089 \\
\hline
\end{tabular}

The Ideal-Solution Equation.-The tendency in recent advanced textbooks ${ }^{7}$ is to present the subject from a different standpoint, namely the ideal-solution equation. ${ }^{8}$ This postulates that, above an ideal solution, the vapor pressure of each molecular species is proportional to its molar fraction in the solution, or,

$$
\left(p_{0}-p\right) / p_{0}=n /(N+n),
$$

where $h$ and $N$ represent the numbers of molecules of non-volatile solute and volatile solvent, respectively, existent in the solution. Although water is not an ideal but an associated solvent, it has been generally accepted that aqueous solutions may be treated as ideal, within the limits of experimental error, provided that the solute concentration is not too high. ${ }^{9}$ Not only has the above ideal equation been extended to aqueous solutions, consequently, but formulas for the representation of osmotic pressure, freezing-point lowering and boiling-point elevation measurements have also been derived therefrom, which have been found to furnish very satisfactory agreement with the experimental data even for fairly concentrated solutions of normal solutes, where the deviations from the "dilute-solution equations" of van't Hoff are quite considerable. ${ }^{10}$

It is important to note the significance which has been attached by workers in these fields to the quantity $N$ in the ideal equation (2) when applied to aqueous solutions. $N$ has been almost universally regarded as still

4 "It must be emphasized that the number of molecules $N$ in the above equation does not denote the number of liquid molecules in the solvent, but only the number of gaseous molecules derivable from the liquid. This caution is necessary, because it has frequently been supposed that the equation enables us to determine the molecular weight of the liquid solvent, which is not the case." Walker, op. cit., p. 194.

${ }^{5}$ Frazer and Lovelace, This Journal, 36, 2439 (1914).

'For further examples see Jellinek, "Lehrbuch d. phys. Chem.," 2, p. 779 (1915).

'E. g., Washburn, "Principles of Physical Chemistry," 1915, p. 146.

8 Van Laar, Z. physik. Chem., 15, 457 (1894); Gibbs, Nature, 60, 461 (1897); G. N. Lewis, Proc. Am. Acad., 43, 259 (1907).

9 The approximate limits for solutes of various types have been indicated by Washburn, op. cit., p. 141.

${ }^{30}$ See Findlay, "Osmotic Pressure,"1919, p. 65; Frazer and Myrick, This JournaL, 38, 1907 (1916). 
representing the number of molecules of solvent actually existent in the solution. ${ }^{11}$ Under this interpretation, since water is admittedly highly associated in the liquid state at ordinary temperatures, while water vapor is to all intents and purposes entirely monomolecular, ${ }^{12}$ the value for $N$ for any given solution must be quite different according to Equation 2 from what it is in Equation 1.

Now it is true that the essential incompatibility of dilute and ideal solution equations for solutions of finite concentration has long been recognized, ${ }^{13}$ but it is also axiomatic that as the solute concentration approaches zero the divergences between them must be vanishingly small. ${ }^{14}$ For an associated solvent such as water, however, the divergences between Equations 1 and 2, if $N$ has not the same significance in each, are fundamental and persist right up to the very highest dilutions of solute. In other words, the ideal-solution equation, as it is at present being interpreted, is in utter disagreement with the dilute-solution equation for all aqueous solutions and hence cannot be in accordance with the existent experimental data. This is a point which has escaped attention hitherto, ${ }^{15}$ but clearly one which requires immediate rectification.

Reconciliation of the Ideal-Solution Equation with the Dilute-Solution Equation and with the Experimental Data.-The necessary reconciliation can be effected by modifying the present erroneous interpretation given to Equation 2 when applied to aqueous solutions. Although liquid water is a mixture of associated molecules of the general type $\left(\mathrm{H}_{2} \mathrm{O}\right)_{q}$ and simple monomolecular $\mathrm{H}_{2} \mathrm{O}$, yet the latter molecular species is the only variety which is appreciably volatile

"An exception is found in the work of Washburn and Heuse, ThIs JournaL, 37, 319 (1917). These investigators noted that it was necessary to employ a value "not appreciably different" from 18 for the molecular weight of water in deriving an equation for calculating osmotic pressures from vapor-pressure depression data.

${ }^{12}$ Kendall, This Journal, 42, 2477 (1920); Menzies, ibid., 43, 851 (1921).

${ }^{13}$ See, particularly, G. N. Lewis, ibid., 30, 668 (1908). The ideal-solution equation is called by Lewis the "modified equation of Raoult," but since the name of Raoult has also been associated with the dilute-solution equation it has been thought advisable to avoid confusion here by giving the formulas under discussion impersonal titles. Raoult first expressed his experimental results by an equation similar in form to Equation 1 above, the subsequent modification to Equation 2 being made empirically to allow the equation to be extended to very concentrated solutions (see Ostwald, ${ }^{86}$ Solutions," 1891, p. 168-73).

${ }^{14}$ Thus Equations 1 and 2 for non-associated liquids obviously become identical when $n$ is negligible in comparison with $N$.

${ }^{10}$ Presumably because the interest of investigators has beenfo cussed almost exclusively upon derived equations (osmotic pressure and freezing-point depression relationships) in which a factor which compensates for association is assumedly present, as will he discussed in a later section. 
at ordinary temperatures. ${ }^{16}$ Hence the vapor pressure $p$ of any aqueous solution must be directly proportional, not to the total mol fraction of solvent present, but to the mol fraction of monomolecular $\mathrm{H}_{2} \mathrm{O}$ existent in the solution. At ordinary temperatures this quantity is undoubtedly extremely minute, ${ }^{17}$ owing to the high degree of association of water in the liquid state. On addition of solute it will be still further reduced, and at first sight this reduction would appear to follow quantitatively the current interpretation of Equation 2.18 We must take into consideration the fact, however, that addition of solute also involves a shift in the equilibrium $\left(\mathrm{H}_{2} \mathrm{O}\right)_{q} \rightleftarrows q\left(\mathrm{H}_{2} \mathrm{O}\right)$, a partial disassociation of complex to simple molecules taking place. The effect of this shift in the association equilibrium upon the vapor-pressure depression equation is examined below.

In pure water, let the mol fraction of non-associated $\mathrm{H}_{2} \mathrm{O}$ equal $\mathrm{N}$, and associated $\left(\mathrm{H}_{2} \mathrm{O}\right)_{q}$ equal $1-N$. In a solution, let the mol fraction of solute be $n$; of $\mathrm{H}_{2} \mathrm{O}, N-x$; of $\left(\mathrm{H}_{2} \mathrm{O}\right)_{q}, 1-N-n+x$.

For both solvent and solution we have, applying the mass-action law to the association equilibrium: (conc. $\left.\mathrm{H}_{2} \mathrm{O}\right)^{q} /$ (conc. $\left.\left(\mathrm{H}_{2} \mathrm{O}\right)_{q}\right)=K$. Hence: $N^{q} /(1-N)=(N-x)^{q} /(1-N-n+x)$.

If sufficiently dilute solutions are considered, powers of $x$ higher than the first can be neglected, and we obtain

$$
x=n N /(N+q(1-N)) .
$$

But if the vapor pressure is due only to non-associated $\mathrm{H}_{2} \mathrm{O}$, its lowering will be proportional to the lowering of the mol fraction of non-associated $\mathrm{H}_{2} \mathrm{O}$ in the solution; i. e., $\left(p_{0}-p\right) / p_{0}=x / N=n /(N+q(1-N))$.

Since $q$ is not known, it is impossible to evaluate this equation directly for any solution, but we can test its applicability by comparing it with the dilute solution equation. For, according to this equation, if $a, b$ and $c$ be the numbers of molecules of solute, $\mathrm{H}_{2} \mathrm{O}$ and $\left(\mathrm{H}_{2} \mathrm{O}\right)_{q}$ respectively in a given weight of solution $\left(p_{0}-p\right) / p_{0}=a /(b+q c)$. And since at high dilutions the shift in the water equilibrium will not significantly

${ }^{16}$ This is indicated by the normal behavior of water vapor (Kendall, loc. cit.). It is of interest to note that all of our currently accepted equations for aqueous solutions are derived with the use of the assumption that water vapor obeys the gas laws exactly, which cannot be valid unless water vapor is essentially monomolecular.

17 Shown by the low vapor pressure of water at ordinary temperatures. From a comparison of the properties of corresponding organic derivatives, we may conclude that monomolecular $\mathrm{H}_{2} \mathrm{O}$ should be more volatile than $\mathrm{H}_{2} \mathrm{~S}$. Walden ( $Z$. physik. Chem., $\mathbf{5 5}, 683$ (1909)) has calculated the boiling point for simple $\mathrm{H}_{2} \mathrm{O}$ as $-120^{\circ}$. Van't Hoff ("Lectures on Theoretical and Physical Chemistry," Part III, p. 50) obtained a still lower value, $-207^{\circ}$.

18 The ratio of the mol fraction of simple $\mathrm{H}_{2} \mathrm{O}$ to the total mol fraction of solvent being regarded as a constant. 
affect the total number of water molecules present, we have (within error limits $), a /(b+q c)=n /(N+q(1-N))$.

Hence the ideal-solution equation is brought into agreement with the dilute-solution equation and consequently also with the experimental data for dilute aqueous solutions.

In applying ideal solution equations to dilute aqueous solutions we must, therefore, proceed just as if water were a non-associated liquid, the shift in the equilibrium $\left(\mathrm{H}_{2} \mathrm{O}\right)_{q} \rightleftarrows q\left(\mathrm{H}_{2} \mathrm{O}\right)$ compensating for the effect of association upon the molar fraction. In other words, it must be recognized that the ratio $p / p_{0}$ is essentially independent of the association factor of the solvent. The effect of this on certain derived relationships may now be briefly considered.

The Ideal Osmotic Pressure Equation.-The failure of the dilute solution equation $\Pi V=R T$ to represent the osmotic pressures of solutions of finite concentration is now generally conceded. In its place we have a more exact equation of the form: ${ }^{19}$

$$
\Pi V_{0}=-R T \ln \left(p / p_{0}\right)
$$

where $V_{0}$ is the molar volume of the solvent, a small correction factor for compressibility being omitted. To this equation the ideal solution principle that the ratio $p / p_{0}$ represents the mol fraction $x$ of volatile solvent has been applied, with the result:

$$
\Pi V_{0}=-R T \ln n x
$$

In the application of this formula to dilute aqueous solutions, considerable energy has been expended in laborious calculations as to the effect of association..$^{20}$ The comforting conclusion has been reached that it makes little difference what value for the association factor for water is taken, since any variation in $x$ (the mol fraction of solvent) on the right-hand side of the equation is counterbalanced by a corresponding variation in $V_{\circ}$ (the molar volume of the solvent) on the left-hand side. ${ }^{21}$

In view of the result derived above, that $p / p_{0}$ is independent of the association factor and that $x$ is consequently a fixed value $e^{22}$ for any given solution, this conclusion would appear to become invalid. Most fortunately (as it happens) a second error has been made which evens up matters. An examination of the thermodynamic cycle upon which Equations 3 and 4 are based ${ }^{23}$ discloses the fact that $V$ orefers to the volume occupied by one

19 Findlay, op. cit., p. 55.

20 For example, see Frazer and Myrick, ThIs Journal, 38, 1907 (1916).

${ }^{21} E$. g., with a weight-normal solution of cane sugar at $20^{\circ}$ the values $\Pi=23.50$ for monomolecular water and $\Pi=23.64$ for water with an association factor 1.65 are obtained. The experimental value is $I I=26.64$ (Findlay, op. cit., p. 64-5).

22 The value obtained by "assuming" all water to be existent as monomolecular $\mathrm{H}_{2} \mathrm{O}$.

${ }^{23}$ See Washburn, op. cit., 1915, p. 409-10. 
gram-molecular-weight of water vapor after condensation, and is therefore also independent of the association factor for liquid water.

It seems almost impossible that such a fundamental point should not have been noticed before, but reference to recent literature will show that the "association factor" is still regarded as a stumbling block in the study of abnormalities in the osmotic pressure in aqueous solutions. Its removal from the sphere of action will, it is hoped, facilitate the long-delayed attack upon the main abnormality-hydration. The early workers ${ }^{24}$ in this field have certainly met with more than their fair share of good fortune in the fact that their assumptions, although founded upon a wrong basis, are practically valid as a consequence of the mutual cancellation of the two errors involved.

The Ideal Freezing-point Depression Equation.-In the application of the ideal solution formula-

$$
\ln x=(Q / R) \cdot\left(I / T-I_{/} / T_{\circ}\right)
$$

for freezing-point depressions, similar mistakes have been made. $Q$ (the molar heat of fusion) has been regarded as a factor varying with association, although as derived in the thermodynamic cycle it refers to one grammolecular-weight of condensed water vapor. In the same way $x$ is considered as a variable, ${ }^{25}$ compensating for variations in $Q$. In actual fact, both $x$ and $Q$ are independent of association in the liquid state, and all values derived with the use of arbitrary association factors (even though they differ but slightly from the correct values) are misleading.

\section{Summary.}

The essential incompatibility of the fundamental ideal-solution equation, as applied at present to dilute aqueous solutions, with the dilute-solution vapor-pressure depression equation and with the results of experiment has been pointed out.

It has been shown that the discrepancy disappears when due notice is taken of the fact that the vapor pressure of water at ordinary temperatures must be ascribed practically entirely to its monomolecular fraction, the shift in the equilibrium $\left(\mathrm{H}_{2} \mathrm{O}\right)_{q}=q\left(\mathrm{H}_{2} \mathrm{O}\right)$ on addition of solute counterbalancing the effect of the association upon the molar fraction.

Some fundamental errors in the present application of ideal osmoticpressure and freezing-point depression equations to dilute aqueous solutions have also been corrected.

NEW YORK, N. Y.

${ }^{24}$ For example, Callendar, Phil. Trans., 209A, 177, 319 (1908); Trans. Faraday Soc., 8, 1 (1912).

${ }^{25}$ Roozeboom, "Heterogene Gleichgewichte," 1904, vol. 2, pp. 306-7. The present author pleads guilty to having himself erred on this point (see Kendall, Booge and Andrews, ThIS Journal, 39, 2310 (1917)), but good company is plentiful. 